\title{
Proposal of a Classification of Analogies
}

\section{DAVId AlVARgonzÁlez}

\author{
Department of Philosophy \\ University of Oviedo Campus de Humanidades, 33011 Oviedo \\ Spain \\ dalvar@uniovi.es
}

\begin{abstract}
In this paper, I will propose a classification of analogies based on their internal structure. Selecting the criteria used in that classification first requires discussing the minimal constitutive parts of any analogy. Accordingly, I will discuss the differences between analogy and similarity and between analogy and "synalogy," and I will stress the importance of the analogy of operations and procedures. Finally, I will set forth a classification of the different types of analogies, which lends itself to a further understanding of the differences between certain modulations of the general idea of analogy, such as archetypes, prototypes, models, simulations, parables, paradigms, canons, maps, thought experiments, myths, utopias, dystopias and fables.
\end{abstract}

Résumé: Dans cet article, je proposerai une classification des analogies en fonction de leur structure interne. La sélection des critères utilisés dans cette classification nécessite d'abord de discuter des parties constantes essentielles de toute analogie. En conséquence, je vais discuter des différences entre l'analogie et la similitude et entre l'analogie et la synalogie, et je vais souligner l'importance de l'analogie des opérations et des procédures. Enfin, je vais présenter une classification des différents types d'analogies, qui permet une meilleure compréhension des différences entre certaines modulations de l'idée générale d'analogie, telles que les archétypes, les prototypes, les modèles, les simulations, les paraboles, les paradigmes, canons, cartes, expériences de pensée, mythes, utopies, dystopies et fables.

Keywords: Analogy, model, myth, simulation, thought experiment, utopia

\section{Introduction}

Years back, Jorge Luis Borges described the division of animals as it appeared in a certain Chinese encyclopedia:

Animals (a) belonging to the emperor, (b) embalmed, (c) tame, (d) sucking pigs, (e) sirens, (f) fabulous, (g) stray dogs, (h) included 
in the present classification, (i) frenzied, (j) innumerable, (k) drawn with a very fine camelhair brush, (l) et cetera, (m) having just broken the water pitcher, (n) that from a long way off look like flies" (Borges 1993, pp. 104).

This whimsical classification differs significantly from the phylogenetic taxonomies of animals based on the theory of evolution, just as there is an epistemic difference between the early alchemists' lists of substances and the current periodic table of elements: the first being laundry lists and the second coherent, essential classifications stemming from scientific principles. Classifying triangles or levers by color or material is extrinsic to geometry and physics, whereas classifying triangles by relative length of side (equilateral, isosceles and scalene) and categorizing levers into three classes by the relative position of their constituent parts are intrinsic to geometry and physics. When seeking to establish a classification of internal structure, as occurs with the parts of triangles (sides, angles) and levers (load, effort and fulcrum) in the foregoing examples, identifying the relevant parts of the structures being classified is key. Once the minimal constitutive parts of a given structure have been correctly detected, it is possible to attain a certain degree of completeness in the classification. Conversely, the potency of a structure-based classification may serve to evaluate the suitability of the foregoing constitutive parts. The structure of this paper rests on the co-implication of these two tasks (classifying and characterizing) as applied to the idea of analogy.

In addition to the overarching goal of coming to a structurebased classification of analogies, in this paper I will first discuss the constituent parts of any analogy. In the first section, I contend that the idea of analogy arises not only from logic, argumentation theory, linguistics, and perception psychology, but that it is also necessary to take into account the existence of analogies appearing in other contexts such as techniques, technologies, arts, religions, laws, and sciences. The second section deals with the differences between analogy and similarity. In the third section, I discuss the difference between analogy and "synalogy." In the fourth and fifth sections, I comment on why asymmetry and same-level relationship are constitutive features of any analogy. In the section sixth, I stress the importance of analogies that compare operations and 
procedures. Finally, in the seventh section, I put forward a proposal for classifying analogies according to their previously discussed internal structure.

\section{The sources of the idea of analogy}

By drawing from certain examples, this section looks to show that a full understanding of the idea of analogy cannot be reached by only considering the contents of logic, argumentation theory, linguistics, and perception psychology, and that the existence of analogies in other contexts, such as in techniques, in the arts, in the rest of the sciences, in technologies, in religion and in ethical, political, moral and juridical practice to name but a few, must also be taken into account. Specifically, analogy cannot be reduced to a variety of argumentation since there are many circumstances in which analogies do not have a primarily argumentative function.

The use of analogies to resolve practical problems can be traced throughout human phylogenies and ontogenesis. Ethologists have recognized the presence of some kind of analogical behavior and reasoning among non-human primates (Thompson and Oden 2000; Oden et al. 2001), while prehistorians and archaeologists have taken for granted the human use of analogies of relations and operations to develop and improve on the most primitive pristine techniques of the Stone Age (Shelley 1999). Furthermore, there is a widespread and well-grounded agreement among cognitive psychologists regarding the central role played by analogy in the learning process of newborns, toddlers, infants, children, adolescents and adults (Gentner and Holyoak 1997).

In historical times, analogy and the proportion between particular beings and situations were recognized as a way to address practical problems (in techniques, engineering, law, rhetoric, war, and policies), and as a tool to assay explanations (in science and philosophy) and discuss practical issues (in politics, philosophy, morality and religion). In legal reasoning, the study of cases (usually actual precedents) has been standard procedure since antiquity both in common law systems (the stare decisis doctrine) where prior cases are the primary source of law and analogies are consistently drawn from such cases, and in civil law systems where 
case analogies are necessary to fill the gaps when the issue at stake is not explicitly dealt with in written law (Weinreb 2005). The central role of metaphor and allegory in persuasion and rhetoric seems incontrovertible. In military studies, ancient battles have frequently been taken as analogues of future confrontations so as to develop new tactics and strategies and evaluate new war scenarios; the same goes for the implementation of new practical policies in peacetime.

Equally incontrovertible is the fertility of certain analogical models and counter-models in the natural sciences. The most wellknown examples of the scientific use of analogies and thought experiments include Galileo's discussion of falling bodies, Stevin's inclined plane, Newton's bodies projected in lines parallel to the horizon, Newton's rotating water bucket, Laplace's genius, Maxwell's demon, impossible thermodynamic "machines," Poincaré's and Reichenbach's flatland, Einstein's chasing a light beam, Einstein's trains and elevators, and Schrödinger's cat, to name but a few. Reduced to a variety of argumentation, the pragmatic and material contents of these scientific analogies may go unnoticed. Indeed, certain analogies and thought experiments have become so familiar that they have shaped our thinking and significantly structured our discourse on relevant issues in science (Brown 1991).

Metaphors, allegories, myths, thought experiments, utopias, parables, fables, models and counter-models have also been frequently used throughout the history of philosophy: Plato's philosophical myths (the ring of Gyges, the Amazons, Atlantis, the androgynes, the cave, etc.), Avicenna's floating man, Buridan's ass, Descartes's evil genius, Leibniz's mill, Locke's prince migrated into the body of a cobbler, Hobbes' Leviathan, renaissance utopias, Putnam's brain-in-a-vat and Twin Earth, Davidson's swamp man, Searle's Chinese room, the Gettier belief argument, and modern dystopias such as Aldous Huxley's Brave New World, may serve as an cursory list of the presence of such procedures in philosophy. Perelman, among others, has highlighted the critical role of analogy in the history of Western philosophy (Perelman 1969). Furthermore, as regards the three great religions of the book, the parables and allegories contained in the holy texts are 
also based on analogies, which serve as a canon of righteous behavior (which means righteous operations and procedures).

As illustrated, analogies may be guided by a wide variety of purposes: they can serve to address practical problems (in techniques, technologies, engineering, law, rhetoric, war, and policies), to assay theoretical explanations (in science and philosophy), to structure new phenomena (in science), and to discuss arguments of varying natures (in politics, philosophy, morality and religion).

The idea of analogy, though, does not boil down to a problem of formal (or informal) logic or argumentation theory since it cuts across a wide variety of human activities. The aforementioned illustrations show that discussing this idea requires that a wide range of disciplines and human activities be taken into consideration. Acknowledging this fact is of vital importance to understanding the argument for the analogy of operations and procedures that I will make below in the sixth section and to generalizing certain findings reached in the theory of argumentation.

\section{The difference between analogy and mere similarity}

The purpose of this section is to state the differences between analogy and mere similarity. Attending to this issue is imperative when discussing the scope of the idea of analogy and the outer edges of the classification of analogies, as proposed below. As found in most treatises, the lexical definitions of analogy always include as their chief feature the comparison and similarity between two or more elements, and, therefore, may induce a conflation of the two concepts. The word "analogy" comes from the Latin analogia, which itself comes from the Greek analogia: the prefix ana- meaning "over" (which is related to the Indo-European root an meaning "over," "up"), the word logos meaning ratio, and the suffix $-i a$, meaning quality. The etymological structure of the word, with the root "logos," already suggests the quality of a ratio among two or more things or concepts. Sufficient in ordinary conversational contexts, such lexical and etymological characterizations fall short when trying to understand the structure of the underlying idea as it has been forged in philosophy. 
Certain cognitive psychologists contend that analogy should be distinguished from mere similarity since "analogy is a clever, sophisticated process used in creative discovery, whereas similarity is a brute perceptual process that we share with the entire animal kingdom" (Gentner and Markman 1997, pp. 45-46). Gentner and Toupin argue that analogy implies some manner of systematicity and is not "a mere assortment of independent facts" (Gentner and Toupin 1986, pp. 280). Developed by cognitive scientists, the higher-level perception theory of analogy states a clear differentiation between perceptual similarity and the higher-level construction of analogies (Mitchell 1993; Hofstadter 1995). From the tenets of structure-mapping theory, Gentner, Rattermann, and Forbus have concluded that similarity-based access to memory depends on what they call "similarity," while similarity of a match (something very close to "analogy") depends on the degree of shared higher-order structures, including causal bindings (Gentner et al. 1993). Irrespective, the perception of similarities between elements and processes can be understood as a constitutive, albeit not distinctive, feature of analogies. Analogies imply similarities between their parts; nevertheless, mere similarity between images, things or processes may also appear amid non-human animals, apart from analogical constructions. In the same vein, in research concerning data analysis, Barbosa and others have argued that similarity refers to instances within the same class while analogy involves different classes (Barbosa et al 2007).

In line with those findings I assume that:

1. Similarity, likeness and resemblance and the related antonyms dissimilarity, unlikeness, and difference are dyadic relationships grounded on direct perceptions. Consequently, the apprehension of similarity and difference is present in actu exercito in the behavioral repertoire of a wide range of non-human animals since it is a capacity humans share with other organisms endowed with a psychological makeup.

2. Analogy, though, is a more complex relationship implying the determination of the relevant constituents of certain wholes and the representation of proportions between them. Consequently, constructing analogical relationships is a distinctive feature of human beings endowed with a language of words - a feature that 
might be shared by certain trained-in-captivity great apes (Thompson and Oden 2000). The pragma-dialectical philosophy of Frans $\mathrm{H}$. van Eemeren defines comparison in terms of relevant similarity (Eemeren and Garssen 2014, pp. 45-49). In structure-mapping theory, analogy implies the existence of shared structural relationships in the mapping of the elements of source and target (Gentner 1983).

In analogy, the relationships of similarity between things and processes are always partial. Were a total similarity to exist between them, we would speak of univocal terms, which are not differentiable. An absolute differentiation and lack of any relatedness is a feature of equivocal terms; analogous terms, for their part, feature a certain similarity and a certain differentiation, with some kind of relatedness. Accordingly, analogy could be understood as an intermediate position between univocity and equivocity. In her meta-psychological theory of analogy, Dedre Gentner characterizes analogy based on its intermediate place between literal similarity (something very close to univocity) and anomaly (which could be seen as a soft version of equivocity) (Gentner 1983, p. 161). Partial likeness is a constitutive feature of analogy but is also a distinctive quality compared to literal similarity, univocity, anomaly, and equivocity.

\section{The difference between analogy and "synalogy"}

The purpose of this section is to argue that certain types of analogies (mainly the so-called analogies of attribution) are not truly analogies and, consequently, should be excluded from the classification of analogies sensu stricto.

In Aquinas, the idea of analogy played an important role since theological anthropology implied that human beings were, in certain features, analogous to God (Lyttkens 1952). By means of analogical arguments, theologians tried to understand both human nature as made in the image of God, and God's attributes as deduced from those of humans. Inspired by Aristotle and partially following Aquinas, Thomas de Vio (also known as Cajetan for having been born in Gaeta, Naples) wrote his famous treatise $O n$ the Analogy of Names (1498), from which I will take the distinc- 
tion of three kinds of analogies, since the structure of his analogy of attribution is still taken into consideration in certain present-day studies. The three kinds move from stronger to weaker:

1. The analogy of proper proportionality, which entails proportionality between terms and relations and the symmetric relationship between the analogues.

2. The analogy of improper proportionality or metaphoric proportionality. In this case, the analogy refers only to the terms, and the relationship between the analogues is not symmetrical: there is a properly used noun and the other analogues are constructed metaphorically based on their relationship to the proper noun.

3 . The analogy of attribution, which is the weakest, most improper, non-symmetrical analogy since it implies the existence of a first analogue or main analogue to which the others refer obliquely, weakly and indirectly (by symbolic or causal relation). Aquinas called this situation an "analogy because of diverse attributions" (De Veritate 21, 4 ad 4 and Principles of Nature Ch. 6, No. 38).

In this case, there is always a main analogue, and the other analogues acquire their meaning through very indirect reference to it. For instance, an animal can, in the proper sense, be said to be "healthy" ("a healthy animal"), but it can also be predicated indirectly on urine ("healthy urine") to mean that it is a sign of health, on medicine ("healthy medicine") to signify that it causes health, and on a diet ("healthy diet") to show that it preserves health. The main analogue is the animal's health, and the other analogues (urine, medicine, diet) acquire their meaning through it (as signs or causes of health). The first analogue is intrinsic, whereas the others are said to arise by "extrinsic denomination."

However, in this paper I maintain that Cajetan's analogy of attribution is not a proper analogy governed by relations of similarity, but is rather a relationship constructed through spatial/temporal or causal contiguity: medicine, urine and diet are called "healthy" by means of "contagion" with the healthy animal. Analogies necessarily imply certain relations of similarity (not contiguity) and, consequently, Cajetan's analogy of attribution is not a true analogy. The relationships characterizing Cajetan's analogies of attribution (Aristotle's four causes) imply a "contiguity adjustment." Taking cues from Gustavo Bueno, I will call this kind of relation- 
ship "synalogy" taken from the Greek "sinalage" meaning "joining" (Bueno 1999). Examples of synalogies include the key and the lock, and the sexual organs during reproduction. Hardly novel, the differences between analogy and synalogy were already at work in Hume's philosophy when he distinguished, in his Treatise on Human Nature, three principles of association: similarity, contiguity, and cause/effect. Similarity relates to analogy while contiguity and cause/effect imply synalogy. The opposition between synalogy and analogy was also acting in Frazer's distinction of sympathetic magic into two types: contagious magic, acting by contiguity, and homoeopathic or imitative magic, acting by similarity, as explained in his famous book The Golden Bough.

The distinction between synalogy and analogy is at work in certain biological and linguistic distinctions. Evolutionary biologists clearly distinguish between analogy and homology. When structures pertaining to organisms of two different species share morphology and perform the same function, they are analogous. If they share a common ancestry, they are homologous even if they are morphologically and functionally different, as is the case in the extremities of whales, horses and monkeys. I understand homology as a sort of processual, temporal contiguity. Two analogous structures may be also homologous (such as the eyes of fishes and birds), but when two structures perform the same function and have different ancestries, biologist use the term "homoplasty," as with the wings of birds and insects. In linguistics, I contend that the distinction between metaphor and metonymy is another modulation of the differences between analogy and synalogy. The structure of metaphors is clearly analogical as I will discuss in section seven below. In the metonymy, though, a thing or concept is designated by the name of a different thing with which it shows certain temporal, spatial or causal contiguity. This occurs when the content is designed with the name of the continent, the product with the name of its origin, and the effect by the name of the cause (and vice versa).

The difference between analogy and synalogy, between similarity and contiguity, affects the relationships between analogates (the "horizontal" one-to-one correspondence between analogates to use Juthe's terminology in Juthe 2016, pp. 83, 109, 431), but it 
does not affect the relationships between their elements (Juthe's "vertical" relationship, Juthe 2016, pp. 83, 109, 431). The parts of each of the analogates can be linked by contiguity (by causality, supervenience, resultance, genus to species etc.), which can be compatible with the correspondence by similarity between analogates, with the similarity of their parts, and with the similarity of the contiguity relationships between their parts. For instance, when establishing the analogy between a map and the terrain, the map has its own parts linked by contiguity, as does the terrain, even though the relationship between the two analogates (the map and the terrain) is not by causality or contiguity. The terrain does not cause the map, and does not adjust by contiguity to the map, although there is a proportional correspondence between the parts of the map and the terrain, and between the contiguity relations of their parts. At this juncture, I follow Holyoak's definition of analogy whereby "two situations are analogous if they share a common pattern of relationships among their constituents even though the elements themselves differ across the two situations" (Holyoak 2005, p. 117).

Interestingly, the conflation of analogy and synalogy is not a mere misunderstanding by medieval philosophers, but still occurs today. Guarini and his team include homology among the relations of similarity (Guarini et al. 2009, p. 94). André Juthe (2016, pp. 60-62) has proposed a certain correspondence between the medieval analogy of attribution and other present-day concepts such as Sacksteder's qualitative analogy (Sacksteder 1974), Michalos' analogy based on analogous properties (Michalos 1969), Hesse's analogical types A and B (Hesse 1965 and 1966), Gentner's and Markman's mere appearance matches (Gentner and Markman 1997) and Holyoak's and Thagard's attribute mapping (Holyoak and Thagard 1995). Nevertheless, this correspondence is disputable since, in the analogy of attribution, the relationship between the analogates is grounded on causes, ends, and agencies, although it is established by contiguity, while in the cases studied by Juthe, the relationship between analogates is always a one-to-one correspondence grounded on partial similarity. 


\section{Analogy and asymmetry}

In what follows, I will argue that asymmetry is a core feature of any analogy. The idea is not new, as the issue was already discussed among Thomistic philosophers. As already stated, Cajetan, following Aquinas (De Veritate, q.2 a11), stated that the most perfect analogy is the analogy of proper proportionality whereby there is complete symmetry between the analogues. Cajetan contended that in this kind of symmetric analogy "no analogue is defined by another, since the definition of one is proportionally the same as that of another" (Cajetan 1498, 1953, p. 77). In his Metaphysical Disputations (1596, d. XXVIII, s.3/11), the famous 16th century Spanish philosopher Francisco Suárez argued that analogy always implies asymmetry and criticized Cajetan's analogy of proper proportionality. According to Suárez, one of the sides of the analogy has to support the weight of the relationship. Following this criticism, I hold that asymmetry is a core feature of true analogy. Perfect symmetry between the analogues makes it possible to explain two or more particular cases using the same underlying principles, but this implies a much closer relationship between the particular cases than mere analogy. The solar system as compared with other multi-planetary systems sharing the universal principles of gravity, and similar triangles sharing the same proportions serve as illustrations of this symmetrical pattern. In such cases, the supposed analogues are instead illustrations of a general law or proportion. In this paper, I hold that asymmetry is a distinctive attribute of analogy. Perfect, symmetric proportionality between two (or more) different objects or situations is but an extreme or "degenerated" modulation of asymmetric analogy. In this context, I use the adjective "degenerated" denotatively, not axiologically, such as when mathematicians characterize the empty set as an extreme, "degenerated set" since it has no elements.

J.E. Adler has defended the significance of asymmetry in analogical arguments, saying that the widely admitted difference between the source and the target of any analogy stands as an indication of the importance of this feature (Adler 2007). The distinction made by William R. Brown between "analans" and 
"analandum" also suggests the asymmetric relationship between the two poles of any analogy (Brown 1989, p. 164).

\section{Same-level relationship}

In the Aristotelian and scholastic tradition, analogical arguments are always understood as from particular to particular. When moving from the universal to the particular, the argument is deemed deductive. In such cases, the particular may serve as an example or illustration of the universal, although examples and illustrations are different from analogical arguments. The derivation of the universal from particular cases is deemed as an inductive procedure. Aristotle, in his treatise On Sophistical Refutations (part 15), discusses the cases where no universal is available: "In cases where there is no term to indicate the universal, still you should avail yourself of the resemblance of the particulars to suit your purpose; for resemblance often escapes detection" (174a3740). Typical Aristotelian analogies are inspired by the mathematical proportionality $\mathrm{A} / \mathrm{B}=\mathrm{C} / \mathrm{D}$. Aristotle used the following example to illustrate a typical analogy: as is a calm in the sea so is windlessness in the air (Topics, I, 17, 108a, 7-11). Consequently, deductive and inductive arguments, although including similarities between premises and conclusions, are clearly differentiated from analogical arguments. André Juthe defends the existence of genuine arguments by analogy that are not reducible to any other type of argument since "their inferences are always from particular to particular, never from general to particular or from particular to general" (Juthe 2005, p. 19). Ionel Apostolatu, in looking at certain dictionaries, concludes that analogy, in its broad sense, implies partial similarity between circumstances, things, and situations moving from particular to particular (Apostolatu 2012, p. 332). Digging further, Juthe, in two later works, characterizes analogical arguments as material/pragmatic same-level reasoning via comparison either from particular to particular or from general to general. Analogies moving from universal to universal are common in ethical analogical argumentation (Juthe 2015, p. 383; 2016, p. 125). In this paper, I assume that this material/pragmatic 
same-level relationship between analogates is a core feature of every analogy (not only of analogical arguments).

\section{Analogy of relations and analogy of operations and proce- dures}

In this section, I should like to touch on the nature of the terms and elements being compared in any analogy. Taking cues from the multiconstraint theory of Holyoak and Thagard (Holyoak and Thagard 1995 and 1997) and from Gentner's structure-mapping theory (Gentner 1983), I assume that the analogy of individual predicates or attributes of objects is not sufficient when characterizing analogies. While analogies do indeed include comparison between objects and attributes of objects, they also require that the relationships between those terms and objects be similar (Perelman 1969). The analogy between the solar system and the atom entails similarity between the relationship of the Sun with the planets and the relationship of the nucleus with electrons (I am citing this illustration salva veritate), although it also implies similarity between the nucleus of the atom and the Sun and a comparison between planets and electrons. In the typical four-term proportions that underlie metaphors, the comparison is not between the terms, but rather between the relationships of the first pair and those of the second. The presence of analogies between relationships is sometimes obscured by the fact that objects and situations have a complex structure and, consequently, comparing certain attributes of complex objects implicitly presupposes comparing the relationships between their parts or attributes. The nature of the compared relationships may be highly diverse involving causality, spatial or temporal adjustment, equality, congruence, kinship, correlation, dependence, to cite but a few possibilities.

As stated, analogy of things includes objects and relations between objects (for instance, situations); however, mention should also be made of the analogy of operations (for instance, the analogy of procedures and processes). In any given language, there may be an "analogy of nouns" (as in Cajetan's treatise), but there may also be an analogy of relations (the analogy of prepositions) and of operations (analogy of actions, analogy of verbs). 
Esa Itkonen has proposed a distinction between an analogy understood as a structure, defined by a static relation between systems, and an analogy as the dynamic process that produces those analogical structures (Itkonen 2005). The distinction is most relevant since analogies are human constructions and, consequently, are always the result of synthetic human procedures. While I subscribe to Itkonen's proposal, my argument for the existence of analogies of procedures implies a different idea: the materials being compared proportionally in certain analogies are operations or behaviors of humans and other animals. In such cases, the analogy's core may depend on the comparison between operations.

In the oft-quoted analogy between the State and the ship ("the governor is to the Republic as the helmsman is to the ship"), the sameness between the two different domains (political and nautical) can be understood as an analogy of relationships. The relationship between the governor and the citizens is deemed similar to the relationship between the helmsman and the seamen. However, a comparison of the operations involved could also be apropos since the operations performed by the prince of the Republic in political praxis are, in certain aspects, like the operations of the helmsman with respect to seamanship. In the analogy between artificial selection and natural selection, the results of the selective operations performed by the human breeder (a farmer or a gardener) are compared with the results obtained by the operations of organisms in the wild. In the famous analogy of Thomson's violinist, the operations of the aborting woman are compared with those of the woman unplugging the violinist. In those cases, the analogy implies the relative proportionality between two (or more) different courses of operations. The same occurs in the analogies between two wars separated by many centuries. Operations, procedures and processes are always directed by a certain finality; they are teleological (either teleonomic, teleoclinical, or teleomorphic) wholes. Consequently, analogy between operations and processes implies a discussion of the proportionality between goals and ends, which does not occur when taking into account the analogy of relationships alone.

Interestingly, most present-day studies have failed to discuss the analogy of operations and procedures. In characterizing analo- 
gies, Paul Bartha, Dedre Gentner and Kenneth J. Kurtz, Marcello Guarini, André Juthe and many others do not even mention them (Bartha 2016, Gentner 1981, Gentner and Kurtz 2006, Guarini 2009, Juthe 2016, p. 62). I suspect certain reasons for this lack of interest about operations. On one hand, research about analogy frequently focuses on theoretical reasoning and argumentation and consequently centers on the analogy of relationships between analogates. Operations are not directly reflected in sentences and propositions since their meaning is circumscribed to performance thereof and, consequently, they may go unnoticed. On the other hand, cognitive psychologists often understand human behavior from a computational perspective that gives priority to the analogy of relationships over the analogy among operations (see, for instance, Gentner et al. 2001).

\section{A classification of the different types of analogies based on their internal structure}

I have hitherto defined analogy as an asymmetrical proportionality stablished among situations, relationships, or operations of relative similar level. Identifying those constituent parts of any analogy makes it possible to construct an internal classification based on three criteria.

The first criterion, arising from the asymmetric relationship between analogates, could be defined as a "directionality criterion" whereby the route linking their similar items can be traveled in two opposite directions. I term the direction from the familiar source to the less known target "extrapolative" moving from the most known to the relatively unknown, from the actual to the possible. In this case, the analogy has an explorative function: the better-known case (source) serves as a platform from which to clarify the structure of the less known, unfamiliar case (target). An illustration of this extrapolative direction of analogies is the analogy between the relatively well-known liquid flow and the unfamiliar electric current that was introduced in the 19th century. Although people did not then know exactly what an electric current was, they made an extrapolation and imagined it as a liquid flow such that voltage was immediately aligned with flow pressure. The 
cases studied by Adler fulfill this explorative function (Adler 2007). In their theories, Ross (Ross 1983, p. 208), Gentner and Holyoak characterize analogies by reference to this explorative or extrapolative function and do not take the opposite direction into separate consideration (Gentner and Holyoak 1997, p. 33).

However, the opposite direction has also been frequented. William R. Brown taking cues from the distinction between explanan$d u m$ and explanans, as it is used in the philosophy of science, introduces the words "analandum," (which is the phenomenon to be analyzed), and "analans" (which is the phenomenon taken to analyze the analandum) (Brown 1989, p. 164). I term this direction "analytical," and although it may appear paradoxical at first glance, it has played an important role in the history of analogies. In such cases, the analans is perhaps still the less known and less familiar part of the analogy - although it is nevertheless understood as an instrument used to identify and analyze the relevant constituents of the analanandum since it is supposed to be easier to manipulate or to understand-perhaps because it is more schematic in certain relevant aspects. When moral philosophers resort to bizarre analogies and thought experiments such as Thomson's violinist (1971) or Parfit's transmogrifying humans (1984) in order to discuss real moral problems, they are invoking bizarre situations (the involuntarily plugged-in violinist or the transmogrified human) to shed light on a real situation (in this case, abortion). Dancy, Jackson, Smith and Burns, among others, have discussed the role of analogy in moral deliberation (Dancy 1985, Jackson 1992, Smith 2002 and Burns 2006).

Although semantical and structural in nature, the directionality criterion introduced in the foregoing classification of analogies implies that analogies may serve two general purposes: the exploration of new domains (targets) or the analysis of a familiar domain (analandum) by taking cues from other analogous contexts (analans). In the first case, the analogy is evaluated by taking into account the fertility of the familiar source so as to organize and structure the target as appropriate. In the second case, the evaluation looks into the analytical utility of the patterns suggested by the "artificial" analans. André Juthe has summarized the classifications proposed by different authors based on the function or 
purpose of analogies as used in argumentation (Juthe 2016, p. 3237). His predictive and creative functions coordinate with the proposed exploratory analogies, while classificatory and heuristic functions can be understood as analytical. An important difference should be highlighted: Juthe is classifying the purposes of analogical argumentation, while I am interested in classifying analogies in any context (logic, techniques, technology, politics, law etc.). Accordingly, he concludes that the purpose of argumentation is probative and consequently finds that the various testing procedures are the primary criterion when classifying analogical arguments. (Juthe 2016, p. 69).

The proposed directionality criterion is reminiscent of Bartha's classification of analogies based on the direction of the determining relation. He distinguished four analogical modes: the first two, "predictive" and "explanatory," approximately correspond to my proposal (extrapolative and analytical). He also introduces a "functional" mode linking the analogates in both directions, and a "correlative" mode in the absence of directions (Bartha 2010, pp. 9599). I dispense with those last two modes since they fail to meet the above-proposed criterion of asymmetry between analogates.

Directionality between analogates should not be confused with other criteria, such as those used in the distinctions between a posteriori and a priori analogies (Govier 1989, 2002, 2010), inductive versus deductive analogies (Barker 1989), and empirical versus normative analogies (Langenbucher 1998; Eemeren and Garssen 2014). These distinctions may be of interest while classifying analogical arguments but are scantly relevant while classifying analogies in general. When taking into consideration certain analogies (and not just arguments by analogy), their a priori and $a$ posteriori aspects, their inductive and deductive character, and their empirical and normative contents are so inextricably connected that such classification criteria are not of much use. An example may serve to illustrate this claim. In the analogy between the brain and the computer, both analogates are quite well known (a priori and a posteriori), both include deductive and inductive suppositions, and both involve normative and empirical contents. Consequently, it is not possible to assess whether this analogy is $a$ priori or a posteriori, inductive or deductive, empirical or norma- 
tive. The same can be said about the majority of the illustrations presented in table 1 below.

The second criterion of classification depends on the domain constraints of the analogates. This criterion takes advantage of André Juthe's distinction between a same-domain analogy and a different-domain analogy (Juthe 2005, 2015, and 2016), and it equally affects the internal structure of analogies. In the samedomain analogy, the two elements belong to the same domain. The analogy between a real plane flying in the air and a scale model plane in a wind tunnel remains in the same domain (aerodynamics) although the results cannot be automatically transferred from one scale to the other. In the different-domain analogy, the components of the analogy belong to wholly different domains. The aforementioned analogy between liquid flow and electric current may serve as an example.

Metaphors can be defined as different-domain analogies, as in Cajetan's analogy of metaphoric proportionality. In those cases, there is one name which is used properly and, from its use, certain other analogues can be constructed in which the name is used improperly or metaphorically. As an illustration, Cajetan cites the following example: laughter is to the face as flowers are to the field and as fortune is to human life. As such, metaphorically one can say that flowers are the laughter of the field, and fortune is the laughter of life. In this kind of analogy, as can be seen, the analogy falls mainly on the terms (laughter $=$ flowers $=$ fortune $)$. The metaphor occurs when the terms of two (or more) different domains are interchanged. Lakoff and Johnson, in their famous book Metaphors We Live By, have shown the extensive presence of a wide variety of metaphors in our daily lives (Lakoff and Johnson 1980). The etymology of the word "metaphor" is consistent with this interpretation of metaphors as different-domain analogies, since the Greek word metaphorá is formed from the suffix "meta-" meaning "after" or "across," and the root "phero" meaning "to carry." Although metaphors usually imply different-domain analogies, not all different-domain analogies have the structure of metaphor as I will show below.

André Juthe has discussed certain previous distinctions that can be coordinated with his proposal for the difference in domains 
(Juthe 2016, pp. 46-47). These include Santibáñez's distinction between analogical argumentation and metaphor (Santibáñez 2010), Weitzenfeld's and Weingartner's difference between homeomorphs and paramorphs (Weitzenfeld 1984, Weingartner 1979), Ruiz's and Luciano's division of within-domain and crossdomain analogies (Ruiz and Luciano 2011), Kokinov's classification of intra- and inter-domain analogies (Kokinov 2013), Garssen's literal versus figurative analogies (Garssen 2009), and Bowdle's and Gentner's differentiation between domain-specific and cross-domain analogies (Bowdle and Gentner 2005).

In this paper, I will argue that different-domain analogies, in turn, can be divided into two subtypes based on the ontological status of the different domains involved. In fact, when evaluating the domains of a given analogy, two situations may happen. Either both domains are real, or one of them is real and the other fictitious. In the first case, we do not abandon the real existing world. For example, the analogy between brains and computers is a different-domain analogy since biology and cybernetics are, in principle, different categories, but both domains are real. In the second case, one of the analogy domains is not real and exists only as something imagined or "sketched," as a product of fantasy. Certain thought experiments with fantastic beings, such as Laplace's genius or Maxwell's demon, may serve as illustrations of analogies having an unreal component.

The last criterion of classification focuses on the elements of comparison of the analogy, which can be either exclusively relational or both relational and operational. An analogy can be centered on domains stated outside the influence of any operational being. For example, the aforementioned analogies between the real plane and the scale model or between liquid flow and electric current focus on comparing certain objects and relations between objects, and such analogies can be understood as independent from the operations of subjects (technicians, scientists, etc.). The analogy between artificial and natural selection, and the analogy of Thomson's violinist mentioned above serve as illustrations of the comparison among operations. The analogy between a utopia and the real world implies analogies between objects and relations; however, it must involve analogies of human operations since the 
core of the analogy requires a comparison of the individual actions and operations of people in the imagined world with those in the real world. In the fields of natural sciences, analogies usually have a relational nature, while in the field of human and ethological sciences, operational analogies are frequent since those sciences need to take into account the behaviors of certain human and nonhuman animals.

To summarize:

1. Based on their function, analogies are extrapolative when they move from a familiar source so as to explore a relatively unknown target. Conversely, they are analytical if they make use of certain features of an artificial analans to shed light on the analandum.

2. The analogates domains can be similar or different. When different, they can either both be real, or one of them can be real (positive) and the other fictitious.

3. In certain cases, comprehending analogies only requires taking into consideration the similarities between terms and relationships of the analogates, while in other cases the similarities between the elements of comparison include the operations of certain involved subjects.

To conclude this paragraph, the following table lays out the three criteria and shows the extent to which they may be useful in understanding the differences and similarities of a wide-ranging sample of analogies. It includes some of the components of the resulting types of analogies and makes careful use of the most suitable words while attending to their lexical structure and etymology. 


\begin{tabular}{|c|c|c|c|c|c|}
\hline \multicolumn{2}{|l|}{ 2. DOMAINS } & \multicolumn{2}{|c|}{$\begin{array}{c}\text { EXTRAPOLATIVE } \\
\text { from source to target }\end{array}$} & \multicolumn{2}{|c|}{$\begin{array}{c}\text { ANALYTICAL } \\
\text { from analans to analandum }\end{array}$} \\
\hline \multicolumn{2}{|c|}{$\begin{array}{l}\text { SAME-DOMAIN ANALO- } \\
\text { GY }\end{array}$} & $\begin{array}{c}\text { I } \\
\text { source as } \\
\text { archetype or } \\
\text { exemplar } \\
\text { Oken's } \\
\text { vertebrate } \\
\text { archetype }\end{array}$ & $\begin{array}{c}\text { II } \\
\text { source as } \\
\text { precedent, } \\
\text { prototype } \\
\text { stare decisis } \\
\text { doctrine } \\
\text { qiyas }\end{array}$ & $\begin{array}{c}\text { III } \\
\text { same-domain } \\
\text { model, } \\
\text { morphism } \\
\text { scale model } \\
\text { plane in the } \\
\text { wind tunnel }\end{array}$ & $\begin{array}{c}\text { IV } \\
\text { same-domain } \\
\text { simulation } \\
\text { learning } \\
\text { simulator }\end{array}$ \\
\hline \multirow{2}{*}{$\begin{array}{l}\text { DIFFERENT- } \\
\text { DOMAIN } \\
\text { ANALOGY }\end{array}$} & $\begin{array}{l}\text { BOTH } \\
\text { REAL }\end{array}$ & $\begin{array}{c}\text { V } \\
\text { source as } \\
\text { paradigm } \\
\text { liquid } \\
\text { flow/electric } \\
\text { current, } \\
\text { Plato's line } \\
\text { analogy }\end{array}$ & $\begin{array}{c}\text { VI } \\
\text { source as } \\
\text { canon } \\
\text { artificial } \\
\text { selection/ } \\
\text { natural } \\
\text { selection }\end{array}$ & $\begin{array}{c}\text { VII } \\
\text { different- } \\
\text { domain model } \\
\text { mapping, } \\
\text { brain/computer } \\
\text { analogy }\end{array}$ & $\begin{array}{c}\text { VIII } \\
\text { different- } \\
\text { domain } \\
\text { simulation } \\
\text { game } \\
\text { simulation, } \\
\text { parables, } \\
\text { Thomson's } \\
\text { violinist }\end{array}$ \\
\hline & $\begin{array}{c}\text { ONE REAL } \\
\text { (POSITIVE) } \\
\text { AND } \\
\text { ANOTHER } \\
\text { FICTITIOUS }\end{array}$ & $\begin{array}{c}\text { IX } \\
\text { extrapolative } \\
\text { thought } \\
\text { experiment } \\
\text { in natural } \\
\text { sciences, } \\
\text { myth } \\
\text { Einstein } \\
\text { riding on a } \\
\text { beam of } \\
\text { light, } \\
\text { Plato's } \\
\text { Timaeus }\end{array}$ & $\begin{array}{c}\mathbf{X} \\
\text { extrapolative } \\
\text { thought } \\
\text { experiments } \\
\text { in social } \\
\text { sciences, } \\
\text { utopia, } \\
\text { soteriological } \\
\text { myths } \\
\text { More's } \\
\text { Utopia, } \\
\text { Skinner's } \\
\text { Walden Two }\end{array}$ & $\begin{array}{c}\text { XI } \\
\text { analytical } \\
\text { thought } \\
\text { experiments in } \\
\text { natural sciences, } \\
\text { myth } \\
\text { EPR paradox, } \\
\text { Plato's myth of } \\
\text { the cave }\end{array}$ & $\begin{array}{c}\text { XII } \\
\text { analytical } \\
\text { thought } \\
\text { experiments } \\
\text { in social } \\
\text { sciences, } \\
\text { myth, fable, } \\
\text { dystopia } \\
\text { Lessing's } \\
\text { "Three rings } \\
\text { parable", } \\
\text { Buridan's ass, } \\
\text { Ethics thought } \\
\text { experiments }\end{array}$ \\
\hline \multicolumn{2}{|c|}{$\begin{array}{l}\text { 3. ELEMENTS OF COM- } \\
\text { PARISON }\end{array}$} & $\begin{array}{c}\text { TERMS \& } \\
\text { RELATIONS } \\
\text { ONLY }\end{array}$ & $\begin{array}{c}\text { TERMS, } \\
\text { RELATIONS \& } \\
\text { OPERATIONS }\end{array}$ & $\begin{array}{c}\text { TERMS \& } \\
\text { RELATIONS } \\
\text { ONLY }\end{array}$ & $\begin{array}{c}\text { TERMS, } \\
\text { RELATIONS \& } \\
\text { OPERATIONS }\end{array}$ \\
\hline
\end{tabular}

(C) David Alvargonzález. Informal Logic, Vol. 40, No. 1 (2020), pp. 109-137 
The first row of Table 1 deals with same-domain analogies (cells I-IV). As already stated, when extrapolative, analogies move from a known, familiar source to a less known, unfamiliar terrain. The first type of analogy establishes the similarity between the terms and relations of a known set of objects (which I term "archetypes" from the Greek "arkhe-" meaning "first," and "typos" meaning "model" or "type") and certain other unfamiliar materials in the same domain (cell I). Oken's vertebrate archetype serves as example since other unknown vertebrates are expected to be similar to the archetype proposed. In the scholastic theory of the analogy between God and humans, God's knowledge is defined as archetypal since it is the original, while creatures' knowledge is ectypal since it is a revealed by God.

I use the word "prototype" (Greek "proto-" meaning "original" or "primitive") to refer to the source in an explorative samedomain analogy when it takes into consideration certain subjects' operations (cell II). Many modern languages reserve the word "prototype" in reference to things made operationally by humans. In the common law system, the use of prior cases in deciding new ones illustrates this type of analogy. In the US, the Roe v. Wade decision is the prototype of subsequent decisions about abortions.

Same-domain analogies can be constructed in the opposite direction, from the analans to the analandum. Same-domain models and simulators can be understood as analans of those types of analogies (cells III and IV). Experimentation with scale model planes in wind tunnels frequently enables relations to be established between their parts, which subsequently prove to be relevant in the design of real planes. The Latin world "modelus" suggests the "lesser size" or relative "schematic character" of the analans in the same domain, while the Latin word "simulare" meaning "imitate" accords with the intentional operational nature assigned to this type of analogy. In a flight simulator, the subject's operations imitate the operations performed in a real plane although a simulator makes it possible to analyze situations that cannot be repeatedly studied in real life (i.e. dangerous threshold situations) (cell IV).

As can be seen, same-domain analogies deal with certain situations bordering on what I have called "perfect symmetry" or 
"shared common principles," and, consequently, they stand at the frontier of genuine analogies. The fact that both parts of the analogy belong to the same domain contributes to this proximity and makes it more likely for them to be governed by the principles of the shared domain (especially if this domain is a scientific one). Nevertheless, I have included them in the table since I contend that asymmetric analogies can be made even without leaving a given domain. Analogies between cases in law demonstrate the existence of such asymmetry.

Most frequently, analogies imply two different domains; the difference in domain between the analogates inevitably entails the asymmetry of their relationship. As already stated, differentdomain analogies may be subdivided into two subtypes, according to the ontological reality of the domains involved. The second row (cells V-VIII) refers to situations where both domains are real albeit different. When a source domain lends its internal organization to another different domain in a non-operational context, I propose calling the source "paradigm" (from the Greek word "paradeigma" meaning "pattern") (cell V). The aforementioned case of liquid flow as the paradigm (pattern) of the electric current serves as an example of two different, albeit real, scientific domains (fluid dynamics and electromagnetism). In Plato's analogy of the divided line (Republic 509d-511e), the source paradigm is geometrical (the proportionally divided line) whereas the target is philosophical (epistemological). The analogy's explorative nature can be observed in the conjectural nature of the noesis placed in the last line segment and in the stipulated proportionality between the various segments. When the extrapolative analogy between different domains requires reference to operations (either human or non-human), the familiar source is taken to be a canon of the target (cell VI). In line with the meaning of the Greek word, " $k a$ non" includes the meaning of "rule"; the source acts as the rule in order to organize or understand the target. As an illustration of this situation, I propose Darwin's use of artificial selection (which is clearly an operational procedure) to understand natural "selection" mutatis mutandis.

Cells VII and VIII include, respectively, different-domain models and simulations. The map is analogous to the terrain; both 
domains are real and different, and, at least in so-called "physical maps," the analogy is mainly between elements and relationships between elements both in the terrain and on the map. I hold that the map, when it is a true map, has an analytical nature (cell VI). I view game theory simulations as illustrations of different-domain, analytical, operational analogies (cell VIII) since they act as instruments for understanding other real operational situations (auctions, market wars, etc.). Parables also fit into this type of analogy. The domains (the parable domain and the real case) usually exhibit differences; the parable is used as an instrument for understanding the real case (analytical direction), and the context is operational in both domains.

Finally, the last row comprises different-domain analogies in which one of the domains is real (positive) and the other is fictitious (cells IX-XII). Due to this ontological gap, asymmetry in such cases is inevitable. Thought experiments and myths pervade the cells in this row since the analogies always imply a comparison between a fictitious domain (be it of myth, fantasy, or merely imagination) and a real one. Myths and thought experiments can have an extrapolative nature when they are used to explore unknown domains. Many of Einstein's thought experiments with trains and light beams have this structure, and Plato, in his Timae$u s$, makes use of several myths to speculate about the structure of the unknown cosmos (cell IX). In an operational context, exploratory analogies with a fictitious component take the form of utopias and soteriological, chiliastic myths, such as More's Utopia and myths regarding the final state or the end of history (cell X). However, the unreal domain of certain analogies may also have an analytical purpose. In the famous EPR paradox, for example, the imagined situation plays the role of a counterexample designed for understanding the inner limits of the quantum mechanics. Plato's allegory of the cave (Republic 514a-520a) uses the fictitious domain of the cave as an instrument to analyze the internal world of shadows (cell XI). Other myths, such as Plato's Ring of Gyges (Republic 360b-d), exemplify situations where the analysis is performed in an operational context through a fantastic domain. In this vein, I understand dystopias less as undesired proposals and more as analytical counterexamples showing the shortcomings and 
contradictions of certain operational projects. Fables also fall under this category of operational, analytical analogies with an unreal domain (cell XII).

\section{Concluding remarks}

In this paper, I have assumed that classifying and characterizing analogies are two co-implicated tasks. I have defended the claim that the sources of the general idea of analogy are wider and more diverse than commonly admitted and do not reduce to logic, argumentation theory, linguistics, or cognitive psychology. Accordingly, I have argued that characterizing and classifying analogies must take into account the varied contexts where analogies take place. I have summarized certain arguments for differentiating analogy and similarity and proposed criteria for differentiating analogy from synalogy (as it appears in the analogy of attribution, biological homology, and linguistic metonymy). I have characterized analogy by asymmetry and relative same-level relationships between analogates. In addition, I have stressed the role played by procedures and operations in the internal structure of certain analogies since operations and procedures can be proportionally compared. Stemming from this characterization of analogies, I have proposed classification thereof based on three criteria: (1) relationship directionality, which is an important issue due to the supposed asymmetry between analogates, (2) analogates' type of domain and proximity, which is related to the relative same-level relationship between them, and (3) the different nature of the compared analogates' elements (terms, relationships, and operations). The co-implication between the characterization and the classification of analogies strongly suggests that the proposed classification will contribute to an understanding of the internal structure of the general idea of analogy.

\section{References}

Adler, J.E. 2007. Asymmetrical analogical arguments. Argumentation 21(1): 83-92. 
Apostolatu, I. 2012. On the history of the concept of 'analogy.' The Greek-Latin antiquity. Procedia. Social and Behavioral Sciences 63: 331-342.

Barbosa, S.D.J., Breitman, K.K., Furtado, A.L., and M.A. Casanova. 2007. Similarity and analogy over application domains. Proceedings of the XXII Simpósio Brasileiro de Bancos de Dados. Brazil: Joao Pessoa.

Barker, S. F. 1989. Analogy in Hume's dialogues. Informal Logic 11(3): 173-184.

Bartha, P. 2010. By parallel reasoning. The construction and evaluation of analogical arguments. Oxford: Oxford University Press.

Bartha, P. 2016. Analogy and analogical reasoning. The Stanford encyclopedia of philosophy, ed. Edward N. Zalta. URL accessed February 1, 2020:

<https://plato.stanford.edu/archives/win2016/entries/reasoninganalogy/>.

Bowdle, B. F. and D. Gentner. 2005. The career of metaphor. Psychological Review 112(1): 193-216.

Borges, J.L. 1993. The analytical language of John Wilkins. In Other inquisitions 1937-1952, J.L. Borges. Texas: University of Texas Press.

Brown, W.R. 1989. Two traditions of analogy. Informal Logic XI (3): 160-172.

Brown, J.R. 1991. The laboratory of the mind: Thought experiments in the natural sciences. London and New York: Routledge.

Bueno, G. 1999. Predicables de la identidad. El Basilisco 25: 3-30.

Burns, L. 2006. Banking on the value of analogies in bioethics. The American Journal of Bioethics 6(6): 63-65.

Cajetan, T. 1498. The analogy of names and the concept of being. Oregon: Wipf \& Stock, 1953.

Dancy, J. 1985. The role of imaginary cases in ethics. Pacific Philosophical Quarterly 66: 141-153.

Dennett, D.C. 1995. Intuition pumps. In The third culture: Beyond the scientific revolution, J. Brockman, 180-197. New York: Simon \& Schuster.

Garssen, B. 2009. Comparing the incomparable: Figurative analogies in a dialectical testing procedure. In Pondering on problems of argumentation: Twenty essays on theoretical issues, eds. F.H. van Eemeren and B. Garssen, 130-140. Series: Argumentation Library, Vol. 14. Berlin: Springer. 
Gentner, D. 1983. Structure-mapping: A theoretical framework for analogy. Cognitive Science 7: 155-170.

Gentner, D. and C. Toupin. 1986. Systematicity and surface similarity in the development of analogy. Cognitive Science 10: 277-300.

Gentner. D., Rattermann, M.J., and K.D. Forbus. 1993. The roles of similarity in transfer: separating retrievability from inferential soundness. Cognitive Psychology 25(4): 524-575.

Gentner, D. and K.J. Holyoak. 1997. Reasoning and learning by analogy. American Psychologist 52(1): 32-34.

Gentner, D., Holyoak, K.J. and B.N. Kokinov, eds. 2001. The analogical mind. Perspectives from cognitive science. Cambridge, Mass: MIT Press.

Gentner, D. and Kurtz, K.J. 2006. Relations, objects, and the composition of analogies. Cognitive Science 30: 609-642.

Gentner, D. and A. Markman. 1997. Structure mapping in analogy and similarity. American Psychologist 52: 45-56.

Govier, T. 1989. Analogies and missing premises. Informal Logic 2(3): 141-152.

Govier, T. 2002. Should a priori analogies be regarded as deductive arguments? Informal Logic 22(2): 155-157.

Govier, T. 2010. A practical study of argument (7th ed.). Belmont, USA: Wadsworth Cengage Learning.

Guarini, M., Butchart, A., Smith, P.S., and A. Moldovan. 2009. Resources for research on analogy: A multi-disciplinary guide. Informal Logic 29(2): 84-197.

Hesse, M. 1965. Aristotle's logic of analogy. The Philosophical Quarterly 15(61): 328-340.

Hesse, M. 1966. Models and analogies in science. Notre Dame, IN: University of Notre Dame Press.

Hofstadter, D.R. 1995. Fluid concepts and creative analogies: Computer models of the fundamental mechanisms of thought. New York. Basic Books.

Holyoak, K.J. 2005. Analogy. In The Cambridge handbook of thinking and reasoning, eds. K.J. Holyoak and R.G. Morrison, 117-142. Cambridge, UK: Cambridge University Press.

Holyoak, K.J. and P. Thagard. 1995. Mental leaps: Analogy in creative thought. Cambridge, MA: MIT Press.

Holyoak, K.J. and P. Thagard. 1997. The analogical mind. American Psychologist 52(1): 35-44.

Itkonen, E. 2005. Analogy as structure and process. Amsterdam and Philadelphia: John Benjamins Pub. Co. 
Jackson, M.W. 1992. The Gedankenexperiment method of ethics. The Journal of Value Inquiry 26: 525-535.

Juthe, L.J.A. 2005. Argument by analogy. Argumentation 19: 1-27.

Juthe, L.J.A. 2015. Analogical argument schemes and complex argumentation. Informal Logic 35(3): 378-445.

Juthe, L.J.A. 2016. Argumentation by analogy: A systematic analytical study of an argument scheme. Doctoral dissertation, University of Amsterdam.

Kokinov, B. 1996. Analogy-making: Psychological data and computational models. In Perspectives on cognitive science 2, ed. Kokinov. NBU Press.

Lakoff, G. and M. Johnson. 1980. Metaphors we live by. Chicago, IL: Chicago University Press.

Langenbucher, K. 1998. Argument by analogy in European law. Cambridge Law New Journal 57(3): 481-521.

López, J.J. 2006. Mapping metaphors and analogies. American Journal of Bioethics 6(6): 61-63.

Lyttkens, H. 1952. The analogy between god and the world. Uppsala: Almqvist and Wiksells.

Mertes, H. 2011. The force of dissimilar analogies in bioethics. Theoretical Medicine and Bioethics 32: 117-128.

Michalos, A.C. 1969. Principles of logic. Englewood Cliffs: Prentice Hall.

Mitchell, M. 1993. Analogy-making as perception: A computer model. Cambridge, MA: MIT Press.

Oden, D.L., Thompson, R.K.R. and D. Premack. 2001. Can an ape reason analogically? Comprehension and production of analogical problems by Sarah, a chimpanzee (Pan troglodytes). In The analogical mind. Perspectives from cognitive science, eds. D. Gentner, K.J. Holyoak and B.N. Kokinov, 471-497. Cambridge, Mass: MIT Press.

Parfit, D. 1984. Reasons and persons. Oxford: Oxford University Press.

Perelman, C. 1969. Analogie et métaphore en science, poésie et philosophie. Revue Internationale de Philosophie 23: 3-15.

Ruiz, F. J. and C. Luciano. 2011. Cross-domain analogies as relating derived relations among two separate relational networks. Journal of the Experimental Analysis of Behavior 95(3): 369-385.

Sachs, J. 2005. Aristotle: Motion and its place in nature. Internet encyclopedia of philosophy. URL accessed February 1, 2020: <http://www.iep.utm.edu/aris-mot/>.

Sacksteder, W. 1974. The logic of analogy. Philosophy \& Rethoric 7(4): 234-252. 
Santibañez, C. 2007. Metaphors and argumentation. In Dissensus and the search for common ground, eds. H.V. Hansen, 1-10. Windsor, ON: OSSA.

Searle, J. 1980. Mind, brains and programs. Behavioral and Brain Sciences 3(3): 417-447.

Shelley, C. 1999. Multiple analogies in archaeology. Philosophy of Science 66: 579-605.

Smith, B. 2002. Analogy in moral deliberation: The role of imagination and theory in ethics. Journal of Medical Ethics 28: 244-248.

Spielthenner, G. 2014. Analogical reasoning in ethics. Ethic Theory and Moral Practice 17: 861-874.

Thompson, R.K.R. and D.L. Oden. 2000. Categorical perception and conceptual judgements by nonhuman primates: The paleological monkey and the analogical ape. Cognitive Science, 24(3): 363-396.

Thomson, J.J. 1971. A defense of abortion. Philosophy and Public Affairs, 1(1): 47-66.

Turing, A. 1952. Can automatic calculating machines be said to think? In The essential Turing: The ideas that give birth to the computer age, B.J. Copeland. Oxford. Oxford University Press.

Van Eemeren, F.H., and B. Garssen. 2014. Argument by analogy in stereotypical argumentative patterns. In Systematic approaches to argument by analogy, ed. H. Ribeiro, 41-56. Dordrecht: Springer.

Weinreb, L.L. 2005. Legal reason: The use of analogy in legal argument. Cambridge: Cambridge University Press.

Weitzenfeld, J. S. 1984. Valid reasoning by analogy. Philosophy of Science 51: 137-149.

Wilkes, K.V. 1988. Real people. Oxford: Clarendon Press. 